\title{
Resposta imune específica de bovinos experimentalmente sensibilizados com inóculos inativados de Mycobacterium bovis e Mycobacterium avium ${ }^{1}$
}

\begin{abstract}
Robson F.C. Almeida ${ }^{2}$, Claudio R. Madruga ${ }^{3}$, Cleber O. Soares ${ }^{3}$, Marta C. Fernandes ${ }^{4}$, Nilton M. Carvalho ${ }^{5}$, Klaudia S.G. Jorge ${ }^{6}$ e Ana Luiza A.R. Osório ${ }^{6 *}$

ABSTRACT.- Almeida R.F.C., Madruga C.R., Soares C.O., Fernandes M.C., Carvalho N.M., Jorge K.S.G. \& Osório A.L.A.R. 2006. [Specific immune response of cattle to experimental sensibilization by inactivated Mycobacterium bovis and Mycobacterium avium.] Resposta imune específica de bovinos experimentalmente sensibilizados com inóculos inativados de Mycobacterium bovis e Mycobacterium avium. Pesquisa Veterinária Brasileira 26(4):195-200. Departamento de Medicina Veterinária da Universidade Federal de Mato Grosso do Sul, Cidade Universitária, Campo Grande, MS 79070-900, Brazil. E-mail: analudmv@nin.ufms.br

The presumptive diagnosis of bovine tuberculosis is based on analysis of the immune response to micobacterial antigens. This experimental simulation of sensibilization by Mycobacterium bovis and Mycobacterium avium in cattle aimed to verify the immune response by both the cervical comparative test and the evolution of the specific production of gamma-interferon, and also to identify interference of unspecified reactions by $M$. avium on the test results. The results support that the experimental animals started a response of delayed hypersensitivity to the inactivated bacilli, and that both diagnostic tests for bovine tuberculosis were efficient for the identification of animals sensitized with $M$. bovis and for discrimination of reactions generated by inoculation of cattle with M. avium.
\end{abstract}

INDEX TERMS: Mycobacterium bovis, Mycobacterium avium, gamma-interferon, tuberculin, immune response.

RESUMO.- O diagnóstico presuntivo da tuberculose bovina é baseado na análise da resposta imune celular a antígenos micobacterianos. Procedeu-se à simulação experimental de sensibilização por Mycobacterium bovis e Mycobacterium avium inativados em bovinos a fim de acompanhar a resposta imune a partir do teste cervical comparativo e da evolução da produção específica de interferon-gama, além de identificar a interferência de reações inespecíficas por $M$. avium nos resultados dos

\footnotetext{
1 Recebido em 11 de outubro de 2005.

Aceito para publicação em 12 de abril de 2006.

${ }^{2}$ Mestrando do Programa Ciência Animal da Universidade Federal de Mato Grosso do Sul (UFMS).

${ }^{3}$ Embrapa Gado de Corte, Caixa Postal 154, Campo Grande, MS 79002970.

${ }^{4}$ Acadêmica de Medicina Veterinária, UFMS.

${ }^{5}$ Laboratório de Anatomia Patológica, Faculdade de Medicina Veterinária e Zootecnia (FAMEZ), UFMS, Cidade Universitária, Campo Grande, MS 79002-900.

${ }^{6}$ Laboratório de Micobacteriologia da FAMEZ, UFMS. *Autor para correspondência: analudmv@nin.ufms.br
}

testes. Verificou-se que os animais desencadearam resposta de hipersensibilidade tardia contra os bacilos inativados, e que ambos os testes diagnósticos da tuberculose bovina foram eficientes na identificação dos animais sensibilizados $\operatorname{com} M$. bovis e na discriminação das reações geradas pela inoculação dos bovinos com M. avium.

TERMOS DE INDEXAÇÃO: Mycobacterium bovis, Mycobacterium avium, interferon-gama, tuberculina, resposta imune.

\section{INTRODUÇÃO}

A tuberculose bovina é uma doença infecto-contagiosa de evolução crônica, determinada por Mycobacterium bovis, que provoca lesões granulomatosas e infecta outros animais de exploração zootécnica, animais silvestres e de zoológico e também o homem (Acha \& Szyfres 1986, Pritchard 1988, Corrêa \& Corrêa 1992).

O agente causal desta infecção é um bacilo intracelular facultativo, que com outras micobactérias causadoras de tuberculose em mamíferos, Mycobacterium tuberculosis, Mycobacterium africanum, Mycobacterium canettii e Mycobacterium microti, constituem o “complexo Mycobacterium tuberculosis" (Shinnick \& Good 
1994, Wards et al. 1995, Roxo 1996, Miltgen et al. 2002). Dentre as espécies de micobactérias não tuberculosas (Runyon 1959), as mais estudadas são as do complexo M. avium-intracellulare (MAC) e M. kansasii (Inderlied et al. 1993, Evans et al. 1996, Mijs et al. 2002, Biet et al. 2005). M. avium é subdividido em quatro subespécies (ssp.): ssp. avium, ssp. paratuberculosis, ssp. silvaticum e, recentemente, ssp. hominissuis (Mijs et al. 2002, Biet et al. 2005). M. avium é o agente da tuberculose em várias espécies de aves, $\mathrm{e}$ o complexo M. avium-intracellulare está associado aos quadros de linfadenites granulomatosas em suínos. As bactérias desse complexo não são patogênicas para os bovinos e bubalinos, com exceção de M. avium ssp. paratuberculosis, causador da doença de Johne (Biet et al. 2005), raramente encontrada no Brasil (RietCorrea 1998, Driemeier et. al. 1999). Entretanto, provocam reações inespecíficas à tuberculinização, dificultando o diagnóstico da tuberculose nessas espécies (Brasil 2003).

O diagnóstico presuntivo da tuberculose bovina é realizado por meio de testes tuberculínicos. Tais testes foram desenhados para determinar a infecção espécie-específica por M. bovis. Por essa razão, a inoculação intradérmica de pequenas quantidades de antígenos micobacterianos gera em 24-72h uma reação inflamatória local naqueles animais que responderam imunologicamente à infecção prévia por M. bovis. A resposta é mediada por linfócitos T (Th1) que migram ao sítio de injeção do antígeno e reconhecem os peptídeos apresentados em conjunção com o complexo de histocompatibilidade principal (MHC) de Classe II na superfície celular de macrófagos. Os linfócitos Th1 liberam citocinas, tais como interleucina-2 (IL-2) e interferon-gama (IFN- $\gamma)$, que agem sobre o endotélio vascular recrutando células do sistema imune para o sítio de deposição do antígeno (Janeway $\&$ Travers 1997). O recrutamento de linfócitos Th1, fagócitos, fluidos e proteínas produz uma lesão visível (Janeway \& Travers 1997, Tizard 2002, Wedlock et al. 2002).

No local da inoculação ocorre edema endurecido, que resulta do processo inflamatório, da deposição de fibrina e da trombose local, o qual atinge sua maior intensidade por volta de $72 \mathrm{~h}$ (Monaghan et al. 1994). Esse edema pode persistir por semanas ou desaparecer gradualmente. Nas reações muito severas, podem ocorrer destruição e necrose tecidual no local da injeção (Monaghan et al. 1994, Tizard 2002). No exame histológico, a reação revela infiltrado de células mononucleares, principalmente macrófagos e linfócitos, e de poucos neutrófilos (Macruz \& Bueno 1963, Monaghan et al. 1994, Roxo et al. 1998, Tizard 2002).

As tuberculinas disponíveis para o diagnóstico indireto in vivo da tuberculose bovina são extratos antigênicos de proteínas purificadas, conhecidas como PPD (purified protein derivative), de isolados AN5 de M. bovis (PPD bovino) e D4 de M. avium (PPD aviário). Embora as tuberculinas sejam descritas como puras, elas são formadas por uma mistura complexa de proteínas, lipídeos, açúcares e ácidos nucléicos, o que inclui uma grande variedade de antígenos, alguns comuns a várias espécies de micobactérias (Monaghan et al. 1994), sendo este um fator que contribui para as reações inespecíficas.

Os testes tuberculínicos podem ser simples ou comparativos. O teste tuberculínico simples utiliza apenas a tuberculina bovina (teste da prega caudal - TPC ou o teste cervical simples TCS), enquanto o teste cervical comparativo (TCC) utiliza as tuberculinas bovina e aviária de forma simultânea. O TCC é mais específico que os testes simples, pois permite distinguir infecção por M. bovis do "complexo MAC" e micobactérias ambientais (OIE 1992, Brasil 2003, Waters et al. 2003).

Recentemente, vários testes in vivo e in vitro para o diagnóstico da infecção por M. bovis foram desenvolvidos, tais como a hipersensibilidade com ESAT-6 (Pollock et al. 2003), linhagens de macrófagos (Ritelli et al 2003), aglutinação em látex (Koo et al. 2004), testes de imunoadsorção enzimática - ELISA (Dunn et al. 2005) e a reação da polimerase em cadeia - PCR (Zumarraga et al. 2005). Entretanto, o que vem sendo mais avaliado é a detecção de IFN- $\gamma$ bovino. $O$ ensaio é realizado in vitro e é baseado na detecção de IFN- $\gamma$ liberado por linfócitos sensibilizados durante incubação com material antigênico que contém antígenos espécie-específicos (Walravens et al. 2002). Os animais infectados com $M$. bovis têm linfócitos Th1 sensibilizados aos antígenos desta micobactéria e liberam IFN- $\gamma$ que será detectado no plasma por ELISA de captura com anticorpo monoclonal (Wood et al. 1990, 1992, Wood \& Rothel 1994, Scacchia et al. 2000, Wood \& Jones 2001, Walravens et al. 2002, Waters et al. 2003).

Os testes indiretos para o diagnóstico da tuberculose bovina são influenciados por fatores biológicos, como a cinética da resposta imune natural induzida pela infecção e reações cruzadas com outros microorganismos que interferem com a especificidade e a mensuração da resposta (Walravens et al. 2002, Cagiola et al. 2004, Gormley et al. 2004).

Os objetivos deste trabalho foram acompanhar a resposta celular aos testes indiretos (IFN- $\gamma$ e TCC) e identificar a interferência de reações inespecíficas por $M$. avium nos resultados desses testes após sensibilização experimental de bovinos por $M$. bovis e M. avium inativados.

\section{MATERIAL E MÉTODOS}

\section{Animais experimentais e inóculo}

Utilizaram-se 26 bovinos mestiços (cruzamento industrial e pardo suíço), machos de 16-20 meses de idade, em bom estado geral e negativos no TCC. Apenas um dos animais (Bov.17) foi reagente para Mycobacterium avium. Os animais ficaram em regime extensivo no hospital veterinário da Universidade Federal de Mato Grosso do Sul (UFMS).

Dos 26 bovinos utilizados no experimento, 16 foram sensibilizados com 10mg de inóculo inativado da amostra AN5 de M. bovis e três com $10 \mathrm{mg}$ da amostra D4 de M. avium, cedidos pelo Laboratório Regional de Apoio Animal - Lara/MG. A inoculação foi realizada na região da barbela por via subcutânea. Os sete animais restantes integraram o grupo-controle negativo para os testes de imunoadsorção enzimática para detecção de interferon-gama (IFN- $\gamma$ ) bovino e do TCC.

\section{Detecção de interferon-gama bovino}

Em todos os animais, o sangue foi coletado a partir do dia da inoculação (antes da sensibilização) e a cada 15 dias até o $60^{\circ}$ dia pósinóculo. A coleta foi feita em tubos heparinizados, mantidos em temperatura ambiente e processados em até $3 \mathrm{~h}$. Volumes de 1,5ml de cada amostra de sangue total foram distribuídos em placas de poliestireno com 24 orifícios para cultura de células. Para cada amostra adicionou-se no orifício $1,100 \mathrm{ml}$ de tampão salino fosfatado (PBS); no orifício 2, $100 \mathrm{ml}$ de PPD aviário; e no orifício 3, 100ml de PPD bovino. As amostras foram homogeneizadas e incubadas por $20 \mathrm{~h}$ a $37^{\circ} \mathrm{C}$, com $5 \%$ de $\mathrm{CO}_{2}$, e o plasma foi removido e congelado a $-80^{\circ} \mathrm{C}$. 
O teste de imunoadsorção enzimática para detecção de IFN- $\gamma$ foi realizado com o kit Bovine Gamma Interferon Test (Bovigam-CSL Veterinary Limited). A execução foi de acordo com as recomendações do fabricante.

\section{Teste cervical comparativo}

As inoculações das tuberculinas (PPD aviária e bovina - Laboratório Tecpar) foram realizadas 60 dias após a sensibilização, por via intradérmica, na dosagem de $0,1 \mathrm{ml}$, na região cervical, em locais previamente demarcados por tricotomia. Antes da inoculação da tuberculina foi realizada a primeira mensuração da espessura da dobra da pele com o auxílio de um cutímetro. Após $72 \mathrm{~h}$ da inoculação, realizou-se nova medida da dobra da pele no local de inoculação das tuberculinas PPD aviária e bovina. A execução e interpretação dos resultados foram de acordo com o regulamento técnico do Programa Nacional de Controle e Erradicação da Brucelose e da Tuberculose Animal (PNCEBT) do Ministério da Agricultura, Pecuária e Abastecimento (Brasil 2001).

Os resultados negativos e inconclusivos foram agrupados na categoria negativos, para efeito de cálculo de concordância entre os métodos de diagnóstico utilizados (Mathias et al. 1995). Utilizou-se a prova binomial para comparar os dois testes diagnósticos (Siegel 1975). Considerou-se nas análises $\alpha=0,05$.

\section{Histopatologia}

Realizou-se biópsia de pele no local da reação ao TCC, após 72h da tuberculinização. Os fragmentos obtidos foram fixados em formol a $10 \%$ por um período mínimo de $48 \mathrm{~h}$. As amostras já fixadas foram processadas, e as lâminas histológicas coradas em hematoxilinaeosina (HE) foram examinadas ao microscópio fotômico.

\section{RESULTADOS}

O Quadro 1 apresenta o resultado do ensaio para a detecção de IFN- $\gamma$ nos bovinos sensibilizados e nos bovinos-controle, antes e após a sensibilização experimental com inóculos inativados AN5 de Mycobacterium bovis e D4 de M. avium. O Quadro 2 apresenta a interpretação do TCC nos bovinos sensibilizados e nos bovinos-controle, após 60 dias da inoculação experimental.

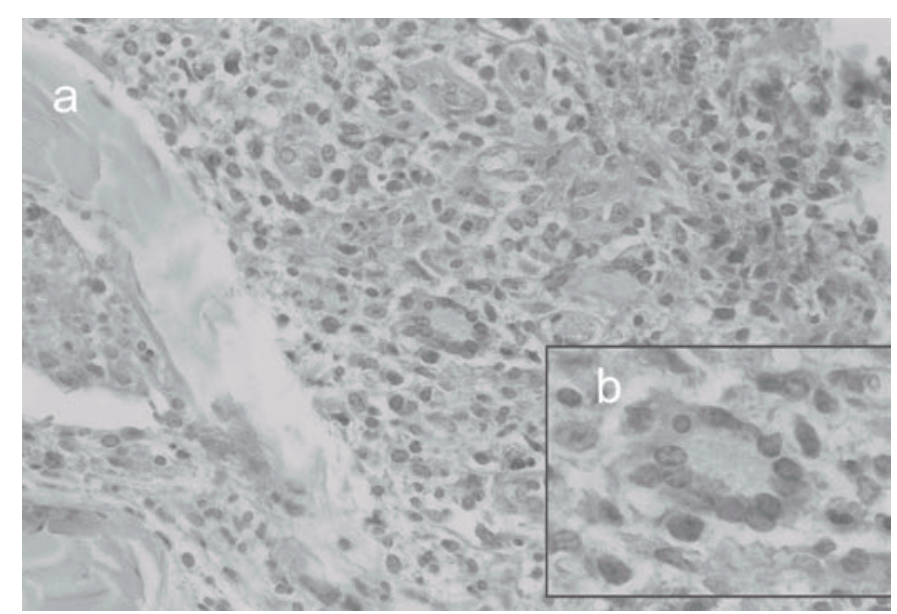

Fig.1. Infiltrado inflamatório com predominância de células mononucleares observado na reação positiva no teste cervical comparativo: (a) diferenciação monócito/macrófago, células epitelióides e células gigantes tipo Langhans; (b) detalhe de célula gigante tipo Langhans. HE, obj.100.
Quadro 1. Reações dos bovinos sensibilizados experimentalmente com inóculos inativados AN5 de Mycobacterium bovis e D4 de Mycobacterium avium no teste de imunoadsorção enzimática (ELISA) para deteç̧ão de interferon-gama

\begin{tabular}{cccccc}
\hline $\begin{array}{c}\text { Animal } \\
n^{\underline{o}}\end{array}$ & $\begin{array}{c}1^{\underline{a}} \text { Colheita } \\
\text { dia zero }\end{array}$ & $\begin{array}{c}2^{\underline{a}} \text { Colheita } \\
\text { dia } 15\end{array}$ & $\begin{array}{c}3^{\text {a }} \text { Colheita } \\
\text { dia } 30\end{array}$ & $\begin{array}{c}4^{\mathrm{a}} \text { Colheita } \\
\text { dia } 45\end{array}$ & $\begin{array}{c}5^{\underline{a}} \text { Colheita } \\
\text { dia } 60\end{array}$ \\
\hline
\end{tabular}

\begin{tabular}{|c|c|c|c|c|c|}
\hline \multicolumn{6}{|c|}{ Bovinos sensibilizados com Mycobacterium bovis } \\
\hline 1 & $-a$ & + & + & + & + \\
\hline 2 & - & + & + & + & + \\
\hline 3 & - & - & + & + & + \\
\hline 4 & - & + & + & + & + \\
\hline 5 & - & - & + & + & + \\
\hline 6 & - & - & + & + & + \\
\hline 7 & - & + & + & + & + \\
\hline 8 & - & + & + & + & + \\
\hline 9 & - & + & + & + & + \\
\hline 10 & - & - & + & + & + \\
\hline 11 & - & + & + & + & + \\
\hline 12 & - & + & + & + & + \\
\hline 13 & - & - & + & + & + \\
\hline 14 & - & - & + & + & + \\
\hline 15 & - & + & + & + & + \\
\hline 16 & - & + & + & + & + \\
\hline \multicolumn{6}{|c|}{ Bovinos sensibilizados com Mycobacterium avium } \\
\hline 17 & $\mathrm{R} / \mathrm{Ma}^{\mathrm{b}}$ & $\mathrm{R} / \mathrm{Ma}$ & $\mathrm{R} / \mathrm{Ma}$ & $\mathrm{R} / \mathrm{Ma}$ & $\mathrm{R} / \mathrm{Ma}$ \\
\hline 18 & - & $\mathrm{R} / \mathrm{Ma}$ & $\mathrm{R} / \mathrm{Ma}$ & $\mathrm{R} / \mathrm{Ma}$ & $\mathrm{R} / \mathrm{Ma}$ \\
\hline 19 & - & $\mathrm{R} / \mathrm{Ma}$ & $\mathrm{R} / \mathrm{Ma}$ & $\mathrm{R} / \mathrm{Ma}$ & $\mathrm{R} / \mathrm{Ma}$ \\
\hline \multicolumn{6}{|c|}{ Bovinos controle } \\
\hline 20 & - & - & - & - & - \\
\hline 21 & - & - & - & - & - \\
\hline 22 & - & - & - & - & - \\
\hline 23 & - & - & - & - & - \\
\hline 24 & - & - & - & - & - \\
\hline 25 & - & - & - & - & - \\
\hline 26 & - & - & - & - & - \\
\hline
\end{tabular}

a - Animais negativos, + animais positivos (reagentes para M. bovis).

${ }^{\mathrm{b}} \mathrm{R} / \mathrm{Ma}=$ animais reagentes para $M$. avium.

Todos os animais inoculados com $M$. bovis apresentaram no TCC sinais de reação inflamatória localizada, de consistência firme, sensível e com aumento de temperatura. Essa constatação foi a mesma tanto nos animais positivos ( $\Delta \mathrm{B}-\Delta \mathrm{A} \geq 4 \mathrm{~mm})$ como nos inconclusivos ( $\triangle \mathrm{B}-\Delta \mathrm{A}$ entre 2 e $3,9 \mathrm{~mm}$ ) (Quadro 2).

Os testes de detecção de IFN- $\gamma$ e o TCC apresentaram concordância de $75 \%$. A prova binomial para um intervalo de confiança de $5 \%$ resultou em $p=0,06$, não havendo diferença significativa entre os resultados dos dois testes.

O exame histológico das biópsias das reações positivas e inconclusivas ao TCC revelou edema, raros polimorfonucleares, reação inflamatória com predominância de células mononucleares em processo de diferenciação para macrófagos, com alguns deles alongados com características de células epitelióides. Algumas reações evidenciaram células gigantes do tipo Langhans, restos celulares e discreta vasculite com áreas de necrose não delimitadas (Fig.1).

\section{DISCUSSÃO}

O ensaio de deteç̧ão de IFN- $\gamma$ identificou como positivos todos os animais sensibilizados com Mycobacterium bovis, em diferentes momentos (Quadro 1), o que possibilitou a determinação precoce da resposta imune dos animais aos antígenos micobac- 
Quadro 2. Resultados da tuberculinização dos bovinos sensibilizados experimentalmente com inóculos inativados AN5 de Mycobacterium bovis e D4 de Mycobacterium avium

\begin{tabular}{|c|c|c|c|c|c|c|c|c|}
\hline \multirow{2}{*}{$\begin{array}{c}\text { Animal } \\
n^{\circ}\end{array}$} & \multicolumn{3}{|c|}{ Tuberculina bovina (mm) } & \multicolumn{3}{|c|}{ Tuberculina aviária (mm) } & \multirow{2}{*}{\multicolumn{2}{|c|}{$\Delta \mathrm{B}-\Delta \mathrm{A}$ Interpretação }} \\
\hline & B Oh & B $72 \mathrm{~h}$ & $\begin{array}{c}\Delta \mathrm{B} \\
\text { (B 72h - B 0h) }\end{array}$ & A Oh & A $72 \mathrm{~h}$ & $\begin{array}{c}\Delta \mathrm{A} \\
2 \mathrm{~h}-\mathrm{A} \text { Oh) }\end{array}$ & & \\
\hline \multicolumn{9}{|c|}{ Bovinos sensibilizados com Mycobacterium bovis } \\
\hline 1 & 6,8 & 17,2 & 10,4 & 9,0 & 11,0 & 2 & 8,4 & Positivo \\
\hline 2 & 5,3 & 10,3 & 5,0 & 5,5 & 7,8 & 2,3 & 2,7 & Inconclusivo \\
\hline 3 & 6,1 & 14,2 & 8,1 & 6,3 & 8,5 & 2,2 & 5,9 & Positivo \\
\hline 4 & 8,0 & 17,5 & 9,5 & 7,0 & 8,9 & 1,9 & 7,6 & Positivo \\
\hline 5 & 7,5 & 17,3 & 9,8 & 8,5 & 9,7 & 1,2 & 8,6 & Positivo \\
\hline 6 & 5,1 & 12,2 & 7,1 & 6,0 & 7,7 & 1,7 & 5,4 & Positivo \\
\hline 7 & 6,5 & 14,0 & 7,5 & 8,0 & 9,0 & 1,0 & 6,5 & Positivo \\
\hline 8 & 6,5 & 12,0 & 5,5 & 7,0 & 8,5 & 1,5 & 4,0 & Positivo \\
\hline 9 & 5,9 & 15,4 & 9,5 & 6,1 & 9,2 & 3,1 & 6,4 & Positivo \\
\hline 10 & 5,3 & 22,2 & 16,9 & 6,2 & 12,8 & 6,6 & 10,3 & Positivo \\
\hline 11 & 7,2 & 17,0 & 9,8 & 8,5 & 10,0 & 1,5 & 8,3 & Positivo \\
\hline 12 & 6,4 & 12,0 & 5,6 & 5,7 & 8,7 & 3,0 & 2,6 & Inconclusivo \\
\hline 13 & 5,8 & 12,7 & 6,9 & 5,3 & 8,7 & 3,4 & 3,5 & Inconclusivo \\
\hline 14 & 12,0 & 18,3 & 6,3 & 7,1 & 11,3 & 4,2 & 2,1 & Inconclusivo \\
\hline 15 & 5,5 & 15,2 & 9,7 & 5,0 & 7,2 & 2,2 & 7,5 & Positivo \\
\hline 16 & 5,2 & 13,8 & 8,6 & 5,1 & 8,8 & 3,7 & 4,9 & Positivo \\
\hline \multicolumn{9}{|c|}{ Bovinos sensibilizados com Mycobacterium avium } \\
\hline 17 & 7,2 & 10,8 & 3,6 & 7,0 & 15,2 & 8,2 & $-4,6$ & Negativo \\
\hline 18 & 5,6 & 6,2 & 0,6 & 5,9 & 11,2 & 5,3 & $-4,7$ & Negativo \\
\hline 19 & 4,8 & 5,2 & 0,4 & 5,3 & 12,8 & 7,5 & $-7,1$ & Negativo \\
\hline \multicolumn{9}{|c|}{ Bovinos-controle } \\
\hline 20 & 4,6 & 6,0 & 1,4 & 5,7 & 6,1 & 0,4 & 1,0 & Negativo \\
\hline 21 & 8,5 & 8,6 & 0,1 & 9,0 & 10,5 & 1,5 & $-1,4$ & Negativo \\
\hline 22 & 5,5 & 5,5 & 0,0 & 7,5 & 6,1 & $-1,4$ & $-1,4$ & Negativo \\
\hline 23 & 5,0 & 6,1 & 1,1 & 4,5 & 5,9 & 1,4 & $-0,3$ & Negativo \\
\hline 24 & 4,1 & 4,6 & 0,5 & 4,5 & 4,6 & 0,1 & 0,4 & Negativo \\
\hline 25 & 5,6 & 7,4 & 1,8 & 5,7 & 6,0 & 0,3 & 1,5 & Negativo \\
\hline 26 & 5,8 & 5,9 & 0,1 & 6,2 & 7,2 & 1,0 & $-0,9$ & Negativo \\
\hline
\end{tabular}

terianos, entre 15 e 30 dias após a sensibilização. Esse resultado está de acordo com Walravens et al. (2002), que, ao avaliarem animais infectados experimentalmente com $M$. bovis, detectaram resposta ao teste de IFN- $\gamma 2$ a 4 semanas após inoculação. Em condições de campo, o uso estratégico desse teste pode fornecer meios para identificação precoce de bovinos infectados com M. bovis, assegurando assim sua remoção do rebanho (Ryan et al 2000, Gormeley et al. 2004).

A identificação de um animal reagente (Bov.17) para M. avium no teste do interferon-gama (Quadro 1), antes da inoculação experimental, sugere tratar-se de infecção por micobactérias ambientais ou do complexo MAC, responsáveis por reações inespecíficas (OIE 1992, Inderlied et al. 1993, Roxo et al. 1998, Brasil 2003, Waters et al. 2003).

O TCC identificou como positivos $75 \%$ dos bovinos sensibilizados com $M$. bovis, e 25\% revelaram reação inconclusiva (Quadro 2). Se esses casos decorressem de infecção natural, os animais seriam, conforme o regulamento técnico do PNCEBT, considerados positivos e sacrificados ou submetidos a um segundo TCC com intervalo mínimo de 60 dias (Brasil 2001). Os Bovinos 2, 12, 13 e 14, embora com diganóstico inconclusivo, revelaram, ao exame histológico da reação cutânea, características iguais às dos animais que apresentaram $\Delta \mathrm{B}>\Delta \mathrm{A} \geq 4$. Ressalta-se que os animais inconclusivos foram positivos no ensaio para detecção de IFN- $\gamma$ após 15 dias da inoculação nos Bovinos 2 e 12 e após 30 dias nos Bovinos 13 e 14.

Cabe destacar que o TCC só foi realizado 60 dias após a sensibilização, o que não permitiu avaliar se esse teste também identificaria a infecção já a partir de 15 dias como ocorreu com a detecção do IFN- $\gamma$. Para esclarecer essa questão seria necessário realizar o TCC em diferentes momentos e grupos experimentais, já que o teste cutâneo não deve ser repetido no mesmo animal em intervalo menor que 60 dias devido à possibilidade de dessensibilização (Langrange \& Hurtrel 1988, Monaghan et al. 1994, Thom et al. 2004).

Os resultados obtidos nos exames histológicos das reações estão de acordo com Macruz \& Bueno (1963), os quais mostram que as reações cutâneas à tuberculinização correspondem histologicamente a processo inflamatório indicativo de alergia. Da mesma forma, Roxo et al. (1998), ao estudarem tais reações em bovinos e bubalinos, encontraram intenso infiltrado celular, com predomínio de mononucleares e, em alguns casos, edema e necrose.

Tendo em vista que os testes indiretos para o diagnóstico da tuberculose bovina são baseados na análise da resposta imunológica celular (IFN- $\gamma$ e DTH) perante os antígenos micobacterianos PPDs bovino e aviário, pode-se afirmar que a detecção de IFN- $\gamma$ e a reação tuberculínica indicam de forma 
fidedigna a sensibilização de bovinos com inóculos AN5 de $M$. bovis e D4 de M. avium, e que ambos os testes são efetivos para discriminar as reações inespecíficas geradas por M. avium.

\section{REFERÊNCIAS}

Acha P.N. \& Szyfres B. 1986. Zoonosis y Enfermidades Transmisibles Comunes al Hombre y a los Animales. Parte I: Bacteriosis - Tuberculosis zoonótica. $2^{\mathrm{a}}$ edicion. Organization Mundial de la Salud, Genova, p.174-185.

Ameni G., Miörner H., Roger F. \& Tibbo M. 2000. Comparison between comparative tuberculin and gamma-interferon tests for the diagnosis of bovine tuberculosis in Ethiopia. Trop. Anim. Health Prod. 32:267-276.

Biet F., Boschiroli M.L., Thorel M.F. \& Guilloteau L.A. 2005. Zoonotic aspects of Mycobacterium bovis and Mycobacterium avium-intracellulare complex (MAC). A Review. Vet Res. 36:411-436.

Brasil 2001. Legislação do programa nacional de controle e erradicação da brucelose e da tuberculose animal - PNCEBT. Ministério da Agricultura, Pecuária e Abastecimento, Brasília. 55p.

Brasil 2003. Manual técnico do programa nacional de controle e erradicação da brucelose e da tuberculose animal - PNCEBT. Ministério da Agricultura, Pecuária e Abastecimento, Brasília. 126p.

Cagiola M., Feliziani F., Severi G., Pasquali P. \& Rutili D. 2004. Analysis of possible factors affecting the specificity of the gamma interferon test in tuberculosis-free cattle herds. Clin. Diagn. Lab. Immunol. 11:952-956.

Corrêa W.M. \& Corrêa C.N.M. 1992. Enfermidades Infecciosas dos Mamíferos Domésticos - Tuberculose. $2^{\underline{a}}$ ed. Editora Médica e Científica, Rio de Janeiro, p.317-337.

Driemeier D., Cruz C.E.F., Gomes M.J., Corbellini P.G., Loretti A.P. \& Colodel E.M. 1999. Aspectos clínicos e patológicos da paratuberculose em bovinos no Rio Grande do Sul. Pesq. Vet. Bras. 19:109-115.

Dunn J.R., Kaneene J.B., Grooms D.L., Bolin S.R., Bolin C.A. \& BruningFann C.S. 2005. Effects of positive results for Mycobacterium avium subsp. paratuberculosis, as determined by microbial culture of feces or antibody ELISA on results of caudal fold tuberculin test and interferon-gamma assay for tuberculosis in cattle. J. Am. Vet. Med. Assoc. 226:429-435.

Evans S.A., Colville A., Evans A.J., Crisp A.J. \& Johnston I.D. 1996. Pulmonary Mycobacterium kansasii infection: comparison of the clinical features, treatment and outcome with pulmonary tuberculosis. Thorax 5:12481252.

Gormley E., Doyle M.B., McGill K., Costello E., Good M. \& Collins J.D. 2004. The effect of the tuberculin test and the consequences of a delay in blood culture on the sensitivity of a gamma-interferon assay for the detection of Mycobacterium bovis infection in cattle. Vet. Immunol. Immunopathol. 28:413-420.

Inderlied C.B., Kemper C.A. \& Bermudez L.E. 1993. The Mycobacterium avium complex. Clin. Microbiol. Rev. 6:266-310.

Janeway-Jr C.A. \& Travers P.O. 1997. O Sistema Imunologico na Saúde e na Doença. $2^{\underline{a}}$ ed. Editora Artes Médicas, Porto Alegre, p.11:9-11:13 (paginação irregular).

Koo H.C., Park Y.H., Ahn J., Waters W.R., Hamilton M.J., Barrington G, Mosaad A.A., Palmer M.V., Shin S. \& Davis W.C. 2004. New latex bead agglutination assay for differential diagnosis of cattle infected with Mycobacterium bovis and Mycobacterium avium subsp. paratuberculosis.Clin. Diagn. Lab. Immunol. 11:1070-1074.

Langrange P.H. \& Hurtrel B. 1988. Anergy and other immunologic disturbance in micobacterial infections, p.171-205. In: Bendinelli M. \& Friedman H. (ed.) Mycobacterium tuberculosis, Interaction with the Immune System. Plenum Press, New York.

Macruz R. \& Bueno P. 1963. Exame histológico da reação cutânea tuberculínica para comprovação do diagnóstico da tuberculose em bovinos. Revta Paulista Med. Vet. 1:27-29.

Mathias L.A., MacMillan A.P., Greiser-Wilke I. \& Moenning E.V. 1995. Comparação entre a reação de fixação de complemento, teste imunoenzimático indireto e teste imunoenzimático competitivo no diagnóstico sorológico da brucelose em bovinos procedentes de rebanhos com histórico da enfermidade. Ars Veterinária, Jaboticabal, 11:4755 .

Mijs W., de Haas P., Rossau R., Van der Laan T., Rigouts L., Portaels F. \& van Soolingen D. 2002. Molecular evidence to support a proposal to reserve the designation Mycobacterium avium subsp. avium for bird-type isolates and "M. avium subsp. hominissuis" for the human/porcine type of $M$. avium. Int. J. Syst. Evol. Microbiol. 52:1505-1518.

Miltgen J., Morrillon M., Koeck J.L., Varnerot A., Briant J.F. \& Nguyen G. 2002. Two cases of pulmonary tuberculosis caused by Mycobacterium tuberculosis subsp. canetti. Emerg. Infect. Dis. 8:1350-1352.

Monaghan M., Doherty M.L., Collins D., Kazda J.D. \& Quinn P.J. 1994. The tuberculin test. Vet. Microbiol. 40:111-124.

OIE 1992. Bovine Tuberculosis. OIE Manual for Diagnosis Techniques of Livestock Diseases. Office International Epizzoties, Paris, p.287-296.

Pollock J.M., McNair J., Bassett H., Cassidy J.P., Costello E., Aggerbeck H., Rosenkrands I. \& Andersen P. 2003. Specific delayed-type hypersensitivity responses to ESAT- 6 identify tuberculosis-infected cattle. J. Clin. Microbiol. 41:1856-1860.

Pritchard D.G. 1988. A century of bovine tuberculosis 1888-1988, conquest and controversy. J. Comp. Pathol. 99:357-399.

Riet-Correa F. 1998. Paratuberculose, p.267-270. In: Riet-Correa F., Schild A.L., Méndez M.C. \& Lemos R.A.A. (ed.) Doenças de Ruminantes e Eqüinos. $2^{\underline{a}}$ ed. Varela, São Paulo. 425p.

Ritelli M., Amadori M., Tagliabue S. \& Pacciarini M.L. 2003. Use of a macrophage cell line for rapid detection of Mycobacterium bovis in diagnostic samples. Vet. Microbiol. 94:105-120.

Roxo E. 1996.Tuberculose bovina. Arqs Inst. Biológico, São Paulo, 63:9197.

Roxo E., Vasconcellos S.A., Pinheiro S.R., Baruselli P.S., Macruz R. \& Leite C.Q.L. 1998. Evaluation of tuberculin skin reaction in buffaloes (Bubalus bubalis). Arqs Inst. Biológico, São Paulo, 65:81-92.

Runyon E.H. 1959. Anonymous mycobacteria in pulmonary disease. Med. Clin. North Am. 43:273-290.

Ryan T.J., Buddle B.M. \& De Lisle G.W. 2000. An evaluation of the gamma interferon test for detecting bovine tuberculosis in cattle 8 to 28 days after tuberculin skin testing. Res. Vet. Sci. 69:57-61.

Scacchia M., Lelli R., Petrini A., Prencipe V., Calistri P. \& Giovannini A. 2000. Use of innovative methods in the erradication of bovine tuberculosis. J. Vet. Med. B. Infect. Dis. Vet. Publ. Hlth 47:321-327.

Shinnick T.M. \& Good R.C. 1994. Mycobacterial taxonomy. Eur. J. Clin. Microbiol. Infect. Dis. 13:884-901.

Siegel S. 1975. Estatística Não-Paramétrica. Editora McGraw-Hill do Brasil, São Paulo, p.39-45.

Thom M., Morgan J.H., Hope J.C., Villarreal-Ramos B., Martin M. \& Howard C.J. 2004. The effect of repeated tuberculin skin testing of cattle on immune responses and disease following experimental infection with Mycobacterium bovis. Vet. Immunol. Immunopathol. 28:399-412.

Tizard I.R. 2002. Imunologia Veterinária - Uma Introdução. 6ª ed. Editora Roca, São Paulo. 531p.

Walravens K., Marché S., Rosseels V., Wellemans V., Boelaert F., Huygen K. $\&$ Godfroid J. 2002. IFN- $\gamma$ diagnostic test in the context of bovine micobacterial infections in Belgium. Vet. Immunol. Immnopathol. 87:401-406.

Wards B.J., Collins D.M. \& Lisle G.W. 1995 Detection of Mycobacterium bovis in tissues by polymerase chain reaction. Vet. Microbiol. 43:227-240.

Waters W.R., Palmer M.V., Whipple D.L., Carlson M.P. \& Nonnecke B.J. 2003. Diagnosis implications of antigen-induced gamma interferon, nitric oxide, and tumor necrosis factor alpha production by peripheral blood mononuclear cells from Mycobacterium bovis- infected cattle. Clin. Diagn. Lab. Immunol. 10:960-966.

Wedlock D.N., Skinner M.A., Lisle G.W. \& Buddle B.M. 2002. Control of 
Mycobacterium bovis infections and the risk to human populations. Microb. Infect. 4:471-480.

Wood P.R. \& Jones S.L. 2001. Bovigam: an in vitro cellular diagnostic test for bovine tuberculosis. Tuberculosis 81:147-155.

Wood P.R. \& Rothel J.S. 1994. In vitro immunodiagnostic assays for bovine tuberculosis. Vet. Microbiol. 40:125-135.

Wood P.R., Corner L.A. \& Plackett P. 1990. Development of a simple, rapid in vitro cellular assay for bovine tuberculosis based on the production of the g-interferon. Res. Vet. Sci. 49:46-49.
Wood P.R., Corner L.A., Rothel J.S., Ripper J.L., Fifis T., McCornick B.S., Francis B., Melville L., Small K., De Witte K., Tolson J., Ryan T.J., Lisle G.W., Cox J.C. \& Jones S.L. 1992. A field evaluation of serological and cellular diagnostic tests for bovine tuberculosis. Vet. Microbiol. 31:7179.

Zumarraga M.J., Meikle V., Bernardelli A., Abdala A., Tarabla H., Romano M.I. \& Cataldi A. 2005. Use of touch-down polymerase chain reaction to enhance the sensitivity of Mycobacterium bovis detection. J. Vet. Diagn. Invest. 17:232-238 